\title{
Influence of mashing profile curve and addition of proteases on the composition of the wort and beer
}

\begin{abstract}
Beer is the most consumed alcoholic beverage in the world. In order to reduce processing time and meet the fast market demand, several measures are taken by the breweries, such as exogenous enzymes supplementation and changes in the mash profile. The present study aims to evaluate the effect of proteolytic step suppression and the addition of exogenous proteases in mashing on wort and beer composition. For that, an experimental design was elaborated, which resulted in the production of four different worts and beers, with and without realization of the proteolytic step during the mashing, and with and without the addition of exogenous proteases. The brewer's worts were analyzed for the following parameters: ${ }^{\circ}$ Plato, extract, total nitrogen and free amino nitrogen content. The amino acids cysteine, histidine, phenylalanine, lysine, tryptophan and arginine were quantified in sweet worts by capillary electrophoresis. The beers produced were analyzed for alcohol content, real extract, total nitrogen and free amino nitrogen content, fermentation efficiency and the mass of coagulable matter. The addition of proteolytic extract promoted higher fermentation efficiency and an increase of the extract, as well as the contents of amino acids and total nitrogen in the sweet wort.
\end{abstract}

Keywords: mashing profile, exogenous protease, wort composition
Volume 5 Issue 2 - 2017

\section{Thiago Rocha dos Santos Mathias,' Matheus Cortes Real Dias Lopes,' Catarina Amorim Oliveira, ${ }^{2}$ Renata Corrêa de Carvalho, ${ }^{3}$ Flávia F de Carvalho Marques, ${ }^{3}$ Eliana Flávia Camporese Sérvulo ${ }^{4}$}

'Laboratory of Fermentation Technology, Federal Institute of Education, Science and Technology of Rio de Janeiro (IFRJ), Brasil ${ }^{2}$ Laboratory of Food Chemistry, Federal Institute of Education, Science and Technology of Rio de Janeiro (IFRJ), Brasil ${ }^{3}$ Laboratory of Fundamental and Applied Analytical Chemistry, Fluminese Federal University (UFF), Brasil

${ }^{4}$ Laboratory of Industrial Microbiology, School of Chemistry, Federal University of Rio de Janeiro (UFRJ), Brasil

Correspondence: Thiago Rocha dos Santos Mathias, Laboratory of Fermentation Technology, Federal Institute of Education, Science and Technology of Rio de Janeiro (IFRJ), Brasil, CEP 20270-02I, Tel +55 2l 2566 7772, Fax +55 2l 3938 7567, Email thiago.mathias@ifrj.edu.br

Received: September 16, 2017 | Published: November 21, 2017
Abbreviations: FAN, free amino nitrogen; Cys, cysteine; His, histidine; Phe, phenylalanine; Lys, lysine, Trp, tryptophan; Arg, arginine; CTAB, cetyltrimethyl ammonium bromide

\section{Introduction}

Beer is the product resulting from the fermentation by brewer's yeast of the wort obtained from malted cereal (barley), which may or may not be added by other cereals or sugar sources (called 'adjuncts'), with the addition of hops. Depending on the raw materials used and the execution of its production process, it is possible for the consumer to appreciate different types and styles of beer, in addition to possible changes in the quality of the drink. ${ }^{1-3}$

For a long time, beer production on artisanal scale was sufficient to supply the drink demand. However, throughout its history beer became a popular drink, becoming today the most consumed alcoholic beverage in the world, having as a consequence the production of beers in large scales, a factor that characterizes the brewer market until nowadays. Due to the great competition in the market and the need to supply to the demand with agility, the large industries usually make diverse adjustments, aiming at the reduction of the process costs or of the production times.

As an example, significant changes in the mash curve profile, such as suppression of the time of protease activity to reduce time and energy expenditure in the process. The profile of the mash curve has a great influence on the composition of the wort and beer, affecting the nitrogen content and the type of nitrogen compounds present, with effect on several characteristics of the drink, such as the flavor (products and byproducts of the fermentation and permanence of non- hydrolyzed insoluble substances); the color (mainly by the release of soluble nitrogen and reducing sugars that will undergo subsequent parallel reactions); the texture (by the presence of proteins and dextrins); foam stability and beer turbidity (also influenced by the protein profile present); caloric power; the alcohol content; and the beverage carbonation. ${ }^{4-6}$

The reduction of mashing time usually promotes problems for the wort and beer, and it is common supplementing the wort with the addition of exogenous enzymes to avoid it. Mainly microbial amylase and proteases are added to improve the hydrolytic process. ${ }^{7}$ Thus, there are important changes in the process, such as: increase in the yield of the mash and the free amino nitrogen content (FAN) present in the wort, as well as increased ethanol production and fermentation productivity. ${ }^{8-12}$

The objective of this study was to evaluate the chemical and physicochemical composition of sweet worts and beers produced from different mash profiles, with and without the addition of exogenous enzyme extract, rich in proteolytic activity.

\section{Materials}

The following raw materials, additives and fermentation agents were used to obtain worts and beers: water filtered on activated charcoal, Pilsen malt (Agromalte $\left.{ }^{\circledR}\right)$, hops (Hallertau Perle, HGV ${ }^{\circledR}$, $9.7 \% \alpha$-acids), proteolytic extract of microbial origin, obtained in previous work (Mathias et al., 2017) and bottom fermenting yeastSaccharomyces cerevisiae (W-34/70, Fermentis $\left.{ }^{\circledR}\right)$. 
For the amino acid quantification in sweet wort, by capillary electrophoresis, namely cysteine (Cys), histidine (His), phenylalanine (Phe), lysine (Lys), tryptophan (Trp) and arginine (Arg), respective analytical standards were used ( $\geq 99 \%$, USP, USA) and ultrapure water (resistivity of $18.2 \mathrm{M} \Omega \mathrm{cm}$ ) produced by the Arium Confort II system (Sartorius, Germany). Sodium phosphate, cetyltrimethyl ammonium bromide (CTAB) and sodium hydroxide (Merck, Brasil) were used in the preparation of the working electrolyte (BGE).

The $\mathrm{pH}$ of the BGE was adjusted using a $\mathrm{pH}$ meter (DM-22, Digimed, Brasil). All solutions (BGE, standard solutions and samples) were filtered using syringe filters (PTFE $0.45 \mu \mathrm{m}$, Agilent, Germany) prior to introduction into the capillary electrophoresis system.

\section{Methodology}

\section{Wort and beer production}

All brewer's worts production was carried out on a laboratory scale from a compilation of scientific literature data, ${ }^{6,13-17}$ with a 1:4 (cereal: water) mixture, enriched with calcium chloride $(0.125 \mathrm{~g} / \mathrm{L})$. The $\mathrm{pH}$ of the medium had its value adjusted to range from 5.2 to 5.4 by the addition of lactic acid P.A. when necessary.

The influence of the addition of exogenous proteolytic extract as well as step suppression of protease activity (inherent to the malt) during the mash was verified. For this, a factorial experimental design was used, with two factors (proteolytic step and protease addition) at two levels (with step/without step - with enzyme/without enzyme), resulting in four experiments, as shown in Table 1. Concentration of enzyme extract was fixed to confer a standard amount of enzyme activity $(0.75 \mathrm{U} / \mathrm{g}$ malt $)$ and the experimental conditions varied only qualitatively by its addition or not. Figure 1 briefly shows the mashing curves.

Table I Experimental design for brewery worts production

\begin{tabular}{llll}
\hline & \multicolumn{2}{l}{ Proteolytic Step } & \multirow{2}{*}{ Proteolytic Extract } \\
\cline { 2 - 3 } & $\mathbf{T}\left({ }^{\circ} \mathbf{C}\right)$ & $\mathbf{t}(\mathbf{m i n})$ & \\
\hline Beer 1 & 45 & 15 & add $(+)$ \\
& 55 & 15 & add $(+)$ \\
Beer 2 & - & & not add $(-)$ \\
Beer 3 & 45 & 15 & not add $(-)$ \\
& 55 & 15 & \\
Beer 4 & - & &
\end{tabular}

The mashout was established by the iodine test (alcoholic iodine solution in $2 \%$ potassium iodide), when it was considered the disappearance of the intense purple coloration (which characterizes the presence of starch) and appearance of yellowish color, typical of iodine solution. After mashing, the wort was clarified using a sieve $(0.6-0.7 \mathrm{~mm})$, and the brewer spent grain was washed with heated water $\left(78^{\circ} \mathrm{C}\right)$, with volume equal to mash water initially used. The wort was centrifuged at $1300 \mathrm{~g}$ for $10 \mathrm{~min}$ for further procedures.

The clarified wort obtained was send to boiling step during 60 minutes with the heating power adjusted to promote no more than $10 \%(\mathrm{v} / \mathrm{v})$ water loss by evaporation. Simultaneously, hops were added and hop mass was calculated as a function of the volume of wort at the start of the boiling, based on Klopper's empirical table, which shows the theoretical equivalence between the concentrations of $\alpha$-acids added to the wort and the bitterness (in BU) generated in the drink, considering an isomerization efficiency of $30 \%$. It was planned to obtain a wort with $9^{\circ}$ Plato and $12 \mathrm{BU}$, which characterize a typical American Light Lager beer.
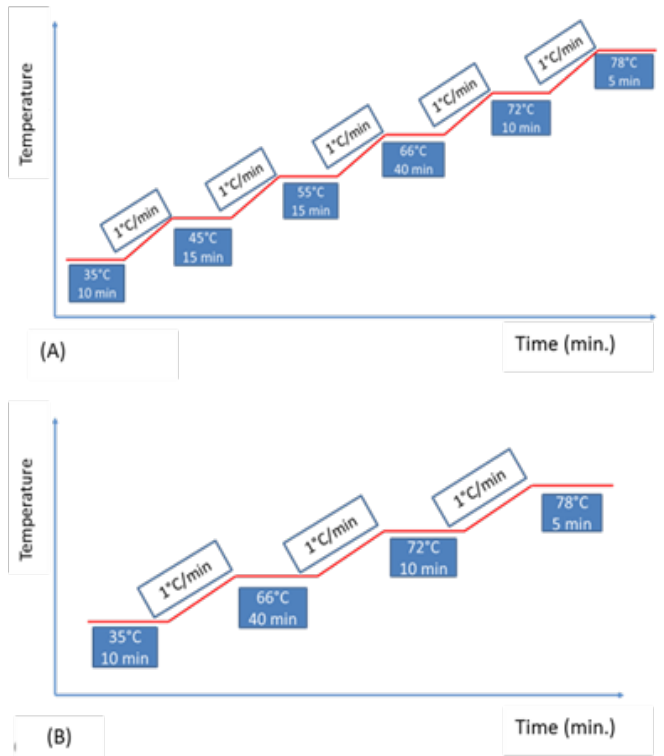

Figure I Mash profiles. (A) with proteolytic step, to obtaining Beers I and 3; (B) without proteolytic step, to obtaining Beers 2 and 4.

After the boiling time, the protein coagulation (hot trub) was deposited by strong manual stirring in a circular movement, to act the centripetal force, reproducing the effect of the equipment adopted in the industrial practice (whirlpool).

After removal of the hot trub, by filtering, the wort was cooled and inoculated with lyophilized brewer's yeast, at a concentration of $1 \mathrm{~g} / \mathrm{L}$ of wort, properly hydrated in $10 \mathrm{ml}$ of cold and sterile water, for each gram of yeast. The fermentation was conducted for 6days at a temperature of approximately $15^{\circ} \mathrm{C}$. After this time, the decanted yeast mass was removed and the green beer matured for 7 days at low temperatures $\left(4^{\circ} \mathrm{C}\right)$.

\section{Analysis of worts and beers}

The sweet worts produced from different time/temperature combinations and added or not of exogenous proteolytic extracts, were submitted to the following analyzes: ${ }^{\circ}$ Plato by refratometric measure; extract ( $\% \mathrm{~m} / \mathrm{m}$ of dissolved solids); total nitrogen content by Kjeldahl method. ${ }^{18,19}$ FAN-free amino nitrogen content-by ninhydrin method. ${ }^{20,21}$ In addition, the nitrogen content lost by coagulation during boiling was determined by the difference between the total nitrogen contents before and after this stage.

The amino acids cysteine, histidine, phenylalanine, lysine, tryptophan and arginine were quantified in sweet worts by capillary electrophoresis in commercial EC 7100 equipment (Agilent, Germany) equipped with a diode arrangement spectrophotometric detector. Separations were conducted in a $60 \mathrm{~cm}$ total length fused silica capillary $(51.5 \mathrm{~cm}$ to the detector-effective length) and $50 \mu \mathrm{m}$ internal diameter. Samples were introduced by hydrodynamic mode at $50 \mathrm{mbar}$ pressure for $15 \mathrm{~s}$ and optimized conditions of the method were: $50 \mathrm{~mol}$ $\mathrm{L}^{-1}$ phosphate buffer containing $0.4 \mathrm{~mol} \mathrm{~L}^{-1} \mathrm{CTAB}$ with $\mathrm{pH}$ adjusted to 12.5 as BGE; applied potential of $-20 \mathrm{kV}$ and temperature of $20^{\circ} \mathrm{C}$. The wavelengths used for detection were 200nm (Lys and Arg); 220nm (Trp, His and Phe) and 230nm (Cys). 
The capillary electrophoresis method validation was performed according to the International Conference on Harmonization ICH Q2, ${ }^{22}$ ANVISA Resolution No. $0899^{23}$ and DOQ-CGCRE-008 ("Guidance on validation of analytical methods") of the National Institute of Metrology, Standardization and Industrial Quality (INMETRO). ${ }^{24,25}$

The beers obtained were analyzed for alcohol content; real extract; and fermentation efficiency in specific equipment (Alcolyzer Beer ME/Anton Paar, DMA 4500M). In addition, total nitrogen content were determined by Kjeldahl method, ${ }^{19}$ FAN-free amino nitrogen content- by the ninhydrin method ${ }^{20,21}$ and the mass of coagulable matter determined after boiling beer samples for two hours and remove the coagulated material.

\section{Results and discussion}

The parameters evaluated for characterization of the produced sweet worts are presented in Table 2, and the data of total nitrogen (N total) and free amino nitrogen (FAN) were analyzed by the Turkey test, for means comparison. The results were compared by the sample pairs, B1/B3 and B2/B4, which differed by the addition of the protease extract; the first pair differs from the second by maintaining the proteolytic step during mashing.

Table 2 Characterization of sweet worts

\begin{tabular}{lllll}
\hline \multirow{2}{*}{ Parameters* } & \multicolumn{4}{l}{ Sweet Wort** } \\
\cline { 2 - 5 } & B1 & B2 & B3 & B4 \\
\hline E $(\% \mathrm{~m} / \mathrm{m})$ & 8,4 & 8,8 & 8,5 & 8,3 \\
${ }^{\circ}$ Plato & 8,4 & 8,9 & 8,8 & 8,5 \\
$\mathrm{~N}_{\text {total }}(\%)$ & $0,040^{2}$ & $0,041^{\mathrm{a}}$ & $0,045^{1}$ & $0,037^{\mathrm{b}}$ \\
$\begin{array}{l}\text { FAN }(\mathrm{mg} / \mathrm{L}) \\
\mathrm{N}_{\text {total }} \text { reduction on boiling } \\
(\%)\end{array}$ & $208^{1}$ & $330^{\mathrm{a}}$ & $250^{1}$ & $212^{\mathrm{b}}$ \\
\hline
\end{tabular}

Different letters and numbers superscripts on the same line correspond to statistically different values, at $5 \%$ of significance

The test was performed in pairs (BI/B3 and B2/B4);

*E, extract

Ntotal, total nitrogen

FAN, free amino nitrogen (in glycine equivalents);

**BI:With proteolytic step and extract; B2: without proteolytic step and with extract; B3: with proteolytic step and without extract; B4: without proteolytic step and without extract.

The addition of exogenous proteases during mashing promoted a slight increase in the extract and the ${ }^{\circ}$ Plato of the sweet wort B2 in relation to the sweet wort B4. In addition, the proteolytic action in the mash also had the same effect, as is observed in wort B3 in relation to the wort B4. These results may be related to the structure of the barley malt grain, whose amylaceous endosperm is trapped in a protein matrix, rich in structural proteins (hordeins), surrounded by a triple protein layer called aleurone. ${ }^{7,26}$ During the mash, the proteolysis consists mainly in the breaking of these protein molecules. In this way, it can be inferred that the proteases added to the media promoted greater action on the protein fraction of the grain, leaving the amylaceous fraction exposed to amylases enzymes action. In general, for the breweries, the extract content has relevance in the calculations of yield and efficiency of the mash step, in addition to presenting correlation with important sensorial characteristics of the beer, mainly with respect to texture aspects.
However, little difference was observed between the extracts of the B1/B3 pair, indicating that the addition of the exogenous proteolytic enzymes had a greater effect when the worts were not submitted to the step of proteases (from the malt) during the mash. With this result, it is assumed that the proteolytic step is sufficient by itself, and the addition of exogenous enzymes is necessary when it is suppressed, aiming to reduce the process time. It is observed that with the exogenous proteolytic extract and without the protease step (B2 wort), an extract value similar to that produced with no exogenous proteolytic extract and protease step was obtained, with a reduction of the process time in 30 minutes.

For the total nitrogen content, there is a small increase, although statistically significant (Turkey's test, Table 2), of the B2 wort relative to the B4 wort. This suggests that the added proteases promoted greater extraction of the nitrogen compounds from the malt to the wort. Even with the low performance of the proteases on the insoluble protein fraction of the malt, the addition of the exogenous proteolytic enzymes promoted changes in the composition of the sweet wort, fundamental for the profile of the soluble nitrogenous compounds present.

The comparative analysis of free amino nitrogen between B2 and B4 worts shows that the highest value was determined when there was supplementation of proteases in the sample (330 and $212 \mathrm{mg} / \mathrm{L}$, respectively), indicating a compensation for proteolytic step suppression. In addition, observing the FAN results for B2 and B3 worts, an expressive increase of this content was observed, even with a reduction of 30 minutes of the processing time. In general, in the condition of low amino acid availability, brewer's yeast presents metabolic alterations, which results in the generation of different fermentation by-products. ${ }^{6}$ In this way, the supplementation of proteases on mash may have a positive effect on sensorial quality of the beer.

Differential losses of total nitrogen during boiling of sweet worts are also evidenced. In the presence of exogenous proteases (B1 and B2) there were smaller percentage losses of this content (Table 2). It is known that during boiling stage, high molar mass proteins tend to lose salvation water, coagulating, in addition to being complexes with each other, with the formation of the so-called hot trub, insoluble, that precipitates and is removed from the wort. ${ }^{27}$ In this way, the addition of exogenous proteolytic enzymes during mash may have promoted a reduction in the molar mass of the proteins present, reducing the intensity with which this coagulation occurred at high temperature. The lower the loss of nitrogen compounds during boiling, the better the nutritional quality of the wort, the performance of the brewer's yeast, and the final product.

In addition, specific amino acids (cysteine, histidine, phenylalanine, lysine, tryptophan and arginine) were determined in sweet worts by capillary electrophoresis. These amino acids are assimilated by yeast during the fermentation process, ${ }^{8,28}$ being used to produce active compounds of the beer flavor. ${ }^{29,30}$ The validated method was linear in the range of $50-1000 \mu \mathrm{g} \mathrm{ml}^{-1}$ for Cys and Lys, $25-1000 \mu \mathrm{gL} \mathrm{mL}^{-1}$ for His and Arg, $10-200 \mu \mathrm{g} \mathrm{mL}^{-1}$ for Trp and 2.5-100 $\mu \mathrm{g} \mathrm{ml}^{-1}$ for Phe, with correlation coefficients greater than 0.9998 . In addition, the proposed method demonstrated good accuracy and recovery of amino acids in sweet worts (83.1-96.2\%).

Figure 2 illustrates the different amino acid compositions in the worts observed in this study. The results indicate that the wort B1 has 
higher concentrations of the amino acids studied; in addition, the amino acid cysteine was only detected in this wort. The concentrations of the amino acid tryptophan in wort B1 and B3 are statistically equivalent, according to the comparison between the mean experimental concentrations by Student's t-test (95\% confidence level). The amino acid content in B2 and B4 worts shows that the highest values were determined in the wort produced with the addition of exogenous proteases (B2 wort), the same result observed when comparing the B1 (with protease) and B3 (without protease).

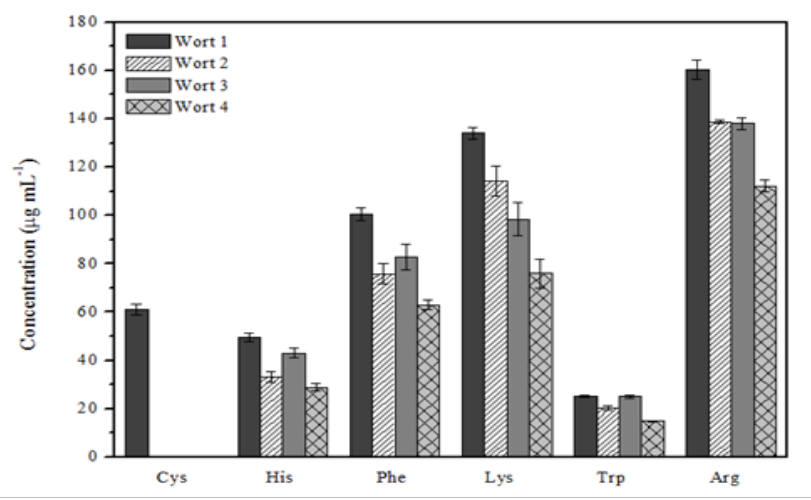

Figure 2 Comparison of the concentrations of the amino acids cysteine, histidine, phenylalanine, lysine, tryptophan and arginine found in sweet worts.

These results confirm that the addition of the proteolytic extract had an effect on the protein fraction of the malt, increasing the content of amino acids and/or other nitrogen compounds of low molar mass, or changing the profile of the nitrogen compounds.

Table 3 presents the parameters of analysis of the four beers produced. There is little variation between the final extracts, although the alcoholic contents were very similar. These values allowed calculating the fermentation efficiencies, whose highest values corresponded to conditions B2 (without proteolytic step and with enzyme supplementation) and B3 (with proteolytic step and without protease supplementation). Additionally, comparing B2 and B4, which were differentiated by the addition of exogenous protease, an increase in fermentation efficiency was observed. Indicating, again, the improvement of the process when there are proteases be they exogenous or endogenous. It is noteworthy that, for B2 beer, the same fermentation efficiency was observed, with a process time reduced by 30minutes (in relation to B3 wort).

It is evident the correlation between total nitrogen and FAN content, with the highest values for beers B1 and B3, both obtained from wort without protease supplementation. However, the highest consumption of amino acids in the fermentation was observed for beer B2, produced by mashing without proteolytic step and with protease supplementation.

Table 3 indicates that the greater mass of coagulable matter by boil was observed for B4 beer (without proteolytic step and without protease supplementation), followed by beers B3, B2 and B1, in this order, the last three being very close values. The coagulable material can be associated to the coagulation of proteins of high molar mass, being the reduction of its concentration beneficial for the colloidal stability of the beverage, avoiding its early turbidity during the period of transport and storage. ${ }^{31}$ Therefore, the results, already expected, indicate the positive effect of both the step of proteases and the supplementation with exogenous proteases on the nitrogenous compounds present in the wort and beer.

Table 3 Caracthrization of beer

\begin{tabular}{lllll}
\hline \multirow{2}{*}{ Parameters* } & \multicolumn{3}{l}{ Beers** } & \\
\cline { 2 - 5 } & B1 & B2 & B3 & B4 \\
\hline Er $(\% \mathrm{~m} / \mathrm{m})$ & 3,1 & 3,5 & 3,4 & 3,2 \\
$\mathrm{~N}_{\text {total }}(\%)$ & 0,027 & 0,020 & 0,028 & 0,025 \\
FAN $(\mathrm{mg} / \mathrm{L})$ & 118 & 89 & 121 & 102 \\
Ethanol $(\% \mathrm{v} / \mathrm{v})$ & 3,6 & 3,7 & 3,8 & 3,7 \\
Coagulable matter $(\mathrm{g} / \mathrm{L})$ & 4,5 & 4,8 & 5,0 & 6,4 \\
Fermentation efficiency $(\%)$ & 92 & 98 & 97 & 91 \\
\hline
\end{tabular}

\section{*E, extract}

Ntotal, total nitrogen

$\mathrm{FAN}$, free amino nitrogen (in glycine equivalents)

Coagulable Matter: Mass of coagulated material after boiling for 2 hours.

**BI: with proteolytic step and extract; B2: without proteolytic step and with extract; B3: with proteolytic step and without extract; B4: without proteolytic step and without extract.

Some authors have evaluated the commercial proteases supplementation for hydrolysis of amylaceous raw materials, whether for the production of beverages or ethanol fuel, in the high gravity process. In the case of wheat, ${ }^{12}$ sorghum, ${ }^{10} \operatorname{corn}^{11,32}$ or traditional barley malt ${ }^{8,9}$ responses obtained were: increase in amino acid concentration; increase in the mashing yield; increased efficiency and productivity of alcoholic fermentation; and, in some cases, the increase of the cellular biomass at the end of the fermentation.

\section{Conclusion}

In summary, the results indicate that the addition of the proteolytic extract had an effect on the protein fraction of the grain, with significant changes in the characteristics of the wort and beer. Its addition promoted increase of the extract, total nitrogen and amino acid content in the sweet wort, and a higher fermentation efficiency. Additionally, there was a reduction of the nitrogen loss in the boiling stage and of the coagulable matter content in beer.

\section{Acknowledgements}

To teaching and research institutions Federal Institute of Rio de Janeiro, Federal University of Rio de Janeiro and Fliminense Federal University.

\section{Conflict of interest}

The author declares no conflict of interest.

\section{References}

1. Tschope EC. Microcervejarias e Cervejarias: A história, a arte e a tecnologia. São Paulo: Editora Aden; 2001.

2. Rehm HJ, Reed G. Biotechnology. 1st ed. Germany: Verlag Chemie; $1983.642 \mathrm{p}$

3. Prescott SC, Dunn CG. Industrial Microbiology. 2nd ed. New York, USA: Mc Graw-Hill; 1949. 923 p. 
4. Mathias TRDS, Aguiar PF, Silva JBA, et al. Brewery waste reuse for protease production by lactic; 2017.

5. Mathias TRS, Mello PPM, Servulo EFC. Nitrogen compounds in brewing wort and beer: A review. Journal of Brewing and Distilling. 2014;5(2):10-17.

6. Briggs DE, Boulton CA, Brookes PA, et al. Brewing: Science and Practice. Cambridge, Woodhead Publishing Limited and Boca Raton. FL, USA: CRC Press LLC; 2004.

7. Lewis MJ, Young TW. Brewing. 2nd ed. USA: Aspen Publishers Inc; 2001.

8. Lei H, Zhao H, Zhao M. Proteases supplementation to high gravity worts enhance fermentation performance of brewer's yeast. Biochemical Engineering Journal. 2013;77(15):1-6.

9. Lei H, Zheng L, Wang C, et al. Effects of worts treated with proteases on the assimilation of free amino acids and fermentation performance of lager yeast. Int J Food Microbiol. 2013;161(2):7683.

10. Perez-Carrilo E, Serna-Saldivar SO, Chuck-Hernandez C, et al. Addition of protease during starch liquefaction affects free amino nitrogen, fusel alcohols and ethanol production of fermented maize and whole and decorticated sorghum mashes. Biochemical Engineering Journal. 2012;67(15):1-9.

11. Klosowski G, Mikulski D, Czuprynski B, et al. Characterization of fermentation of high-gravity maize mashes with the application of pullulanase, proteolytic enzymes and enzymes degrading nonstarch polysaccharides. J Biosci Bioeng. 2010;109(5):466-471.

12. Jones AM, Ingledew WM. Fermentation of very high gravity wheat mash prepared using fresh yeast autolysate. Bioresource Technology. 1994;50(2):97-101.

13. Dragone G, Silva JBA. Cerveja. Em: Venturini-Filho, editors. V1: São Paulo, Brasil: Bebidas Alcoólicas Ciência e Tecnologia; 2010. $461 \mathrm{p}$.

14. Priest FG, Stewart GG. Handbook of Brewing. 2nd ed. Florida: CRC Press and Taylor \& Francis Group, ISA; 2006. 829 p.

15. Bamforth CW. Beer: Tap into the Art and Science of Brewing. 2nd ed. New York: USA: Oxford University Press; 2003. 233 p.

16. Lima UA, Aquarone E, Borzani W, et al. Biotecnologia Industrial. In: Editora Edgard Blucher, Processos Fermentativos e Enzimáticos. São Paulo, Brasil; 2001.

17. Kunze W. Technology Brewing and Malting. 2nd ed. Germany: VLB; $1999.726 \mathrm{p}$.
18. AOAC. Official Method 923.03. Ash of flour: direct method. Rockville, USA: MD; 1990.

19. AOAC. Official Method 935.28-29. Moisture in malt: gravimetric method. Rockville, USA: MD; 1990.

20. Analytica-EBC. 7th ed. Sections 3.3.1 and 4.3.1. European Brewery Convention (EBC). Nurnberg, Fachverlag Hans Carl, Germany; 2008.

21. ASBC Wort-12. Free amino nitrogen (international method). St. Paul, USA: MN; 1976.

22. ICH. Validation of Analytical Procedures: Text and Methodology, Q2 (R1); 2005.

23. Brasil. Resolução no 899 , de 29 de maio de 2003. Guia para validação de métodos analíticos e bioanalíticos. Agência Nacional de Vigilância Sanitária, Brasília; 2003.

24. Brasil. Guidance on validation of analytical methods. DOQCGCRE- 008 (Inmetro). 2011.

25. Brasil. Documento de caráter orientativo. Orientação sobre validação de métodos analíticos. Instituto nacional de metrologia, Normalização e Qualidade Industrial; 2011.

26. Hughes PS. Preparative regime for the purification of bitter acids derived from hops (Humulus lupulus L.). Journal of Chromatography A. 1996;731(1-2):327-330.

27. Barchet R. Cold Trub: Implications for finished beer and methods of removal. Brewing Techniques. 1994;2(2).

28. Jones M, Pierce J. Absorption of amino acids from worts by yeast. J Inst Brew. 1964;70:307-315.

29. Turkia H, Sirén H, Penttilä $M$, et al. Capillary electrophoresis with laser-induced fluorescence detection for studying amino acid uptake by yeast during beer fermentation. Talanta. 2015;131:366371.

30. Brányik T, Vicente AA, Dostálek $P$, et al. A review of flavour formation in continuous beer fermentations. J Inst Brew. 2008;114(1):3-13.

31. Bamforth CW. Current perspectives on the role of enzymes in brewing. Journal of Cereal Science. 2009;50(3):353-357.

32. Johnston DB, Mc Aloon AJ. Protease increase fermentation rate and ethanol yield in dry-grind ethanol production. Bioresource Technology. 2014;154:18-25. 